\title{
Identification and Characterization of Berberine in Tinospora cordifolia by Liquid Chromatography Quadrupole Time of Flight Mass Spectrometry (LC MS/MS Q-tof) and Evaluation of its anti Inflammatory Potential
}

\author{
Mohind C. Mohan, Anu P. Abhimannue, Prakash Kumar B*
}

\section{Mohind C. Mohan, Anu P. Abhimannue, Prakash Kumar B*}

\begin{abstract}
Inflammation Research Lab, School of Biosciences, Mahatma Gandhi University, Kerala, INDIA.
\end{abstract}

\section{Correspondence}

Prakash Kumar B

Associate Professor in biochemistry, School of Biosciences, Mahatma Gandhi University, Kottayam, Kerala, INDIA.

Phone no: +91-9447959320

Orcid ID: 0000-0001-9171-3230

E-mail: prakashkumar@mgu.ac.in

History

- Submission Date: 03-12-16;

- Review completed: 21-01-17;

- Accepted Date: 13-03-17

DOI : 10.5530/pj.2017.3.59

Article Available online

http://www.phcogj.com/v9/i3

Copyright

(C) 2017 Phcog.Net. This is an openaccess article distributed under the terms of the Creative Commons Attribution 4.0 International license.

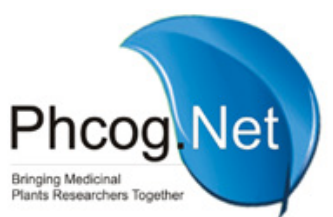

\begin{abstract}
Introduction: Tinospora cordifolia (Willd.) Miers ex Hook $F$ and Thomas commonly called as gudduchi or amrita is a widely used plant in traditional medicinal system of Ayurveda. A UPLC MS/MS Q-tof method for the identification and characterization of berberine in Tinospora cordifolia (Willd.) Miers. ex HooK.F. and Thomas. and to evaluate the anti inflammatory potential of bioactive fraction. Materials and Methods: The presence of berberine in Tinospora cordifolia was determined by HPLC and was subsequently isolated by HPTLC. The anti inflammatory property of the fraction containing berberine was demonstrated to have an inhibitory activity on 5 lipoxygenase, an enzyme involved in inflammatory pathway and its $I C_{50}$ value was obtained. The binding interactions between berberine and 5-LOX were demonstrated by docking studies. Result: The presence of berberine in Tinospora cordifolia methanolic extract was identified by HPLC and HPTLC analysis and confirmed by UPLC MS/ MS Q-tof. The fraction containing berberine inhibited 5-LOX with an $I C_{50}$ of $0.041 \pm 0.0003 \mu \mathrm{g} / \mathrm{mL}$ as compared to that of NDGA (positive control) which showed an $\mathrm{IC}_{50}$ of $2.75 \pm 0.05 \mu \mathrm{g} / \mathrm{mL}$. Molecular docking of berberine with 5 -LOX showed a binding energy of $-8.942 \pm 0.039665 \mathrm{kcal} / \mathrm{mol}$ and $\mathrm{Ki}$ of $273.16 \pm 3.026 \mathrm{nM}$ as compared to the NDGA which has a binding energy of $-7.186 \pm 0.170503 \mathrm{kcal} / \mathrm{mol}$ and $\mathrm{Ki} 5.604 \pm 1.618 \mu \mathrm{M}$. Conclusion: Tinospora cordifolia can be used as a source of berberine and possible anti inflammatory activity of Tinospora cordifolia may be attributed to the presence of berberine.

Key words: Tinospora cordifolia, Mass Spectrometry, 5 Lipoxygenase, Berberine, Molecular Docking.
\end{abstract}

\section{INTRODUCTION}

Tinospora cordifolia (Willd.) Miers ex Hook F and Thomas commonly called as gudduchi or amrita is a widely used plant in traditional medicinal system of Ayurveda. ${ }^{1}$ The plant has been used for centuries for the treatment of various ailments. ${ }^{2}$ It has been reported to have anti-allergic, anti-arthritic, anti-diabetic, antiinflammatory, anti-oxidant, anti-spasmodic, anti-periodic, ${ }^{3}$ radio protective ${ }^{4}$ properties. Various compounds have been isolated and identified from the plant.

Berberine is an isoquinoline alkaloid found in various plantsandhas been usedintraditionalIndianandChinese medicines having wide range of pharmacological actions against gastroenteritis, diarrhea, hyperlipidemia, obesity, fatty liver, coronary artery diseases, hypertension, diabetes and metabolic syndrome, polycystic ovary, Alzheimer's disease and in cancer. ${ }^{5-7}$ HPLC determination of berberine in plants extracts have been described earlier. ${ }^{8}$ LC MS/MS multiple mass spectrometry is an highly effective tool in structural characterization of low molecular weight compounds. ${ }^{9,10}$ 5-Lipoxygenase is a key enzyme involved in pathophysiology of inflammation. ${ }^{11}$ Biomolecules which can inhibit lipoxygenase have potential therapeutic role in controlling various inflammatory diseases including cancer. $^{12}$

The study has led to identification of berberine in Tinospora cordifolia by LC MS/MS Q-tof and the bioactivity of the fraction containing berberine was evaluated for anti inflammatory potential by inhibition of 5-LOX.

\section{MATERIALS AND METHODS}

HPLC analysis was done using Shimadzu LC20AP HPLC system using Enable C18 G250 X 4.6mm column having particle size $5 \mu \mathrm{m}$ and pore size $120 \mathrm{~A}^{\circ}$ and SPD20A UV-VIS detector (Shimadzu, Japan), HPTLC was from Camag, Switzerland. HPTLC system consisting of Linomet TLC sample applicator to spot the sample and Wincats ${ }^{\mathrm{TM}}$ software were used for spectral scanning of TLC plates. Aluminum coated with silica gel 256GF TLC plates (mesh size $60 \mathrm{~A}^{\circ}$, layer thickness of $200 \mu \mathrm{m}$ and particle size of 8-12 $\mu \mathrm{m}$ ) was purchased from Sigma -Aldrich, USA. UPLC MS/MS Q-tof analysis was carried out in Waters Xevo G2-Q-tof mass spectrometer with ACQUITY UPLC ${ }^{\mathrm{TM}}$ BEH C18 column hav-

Cite this article: Mohan MC, Abhimannue AP, Prakash KB. Identification and Characterization of Berberine in Tinospora cordifolia by Liquid Chromatography Quadrupole Time of Flight Mass Spectrometry (LC MS/MS Q-tof) and Evaluation of its anti Inflammatory Potential. Pharmacogn J. 2017;9(3):350-5. 
ing dimensions $50 \mathrm{~mm} \times 2.1 \mathrm{~mm} \times 1.7 \mu \mathrm{m}$ and Mass Lynx V 4.1 software (Waters, MA, USA).

Berberine standard was from Sigma-Aldrich, MO, USA. LC-MS grade solvents were purchased from Fischer Scientific (New Jersey, USA). All the solvents used were of HPLC grade and was purchased from Sigma-Aldrich, MO, USA. 5-Lipoxygenase and NDGA was procured from Cayman chemicals, MI, USA. Xylenol orange, ferrous sulphate and sulphuric acid was from Himedia chemicals, India. The structure of 5 LOX was downloaded from protein data base (http://www.rcsb.org/pdb/ explore.do?structureId=3v99) with PDB ID: 3V99.

\section{Plant material}

The plant materials were collected from parts of Kottayam region of Kerala, India and were identified by taxonomist at Department of Botany, St.Thomas College, and Pala, India. A Voucher specimen was deposited and voucher number (JA17151) was obtained. The plant stem was cleaned, dried and powdered and stored at $-20^{\circ} \mathrm{C}$.

\section{Extraction and isolation}

The shade dried stem was powdered, weighed and $20 \mathrm{~g}$ was used for further extraction. First, the powder was defatted with hexane, followed by soxhlet extraction for $24 \mathrm{hrs}$ with methanol. After extraction, methanol was removed by rotary evaporation and the remaining extract having a percentage yield of $6.94 \%$ was lyophilized and stored at $-20^{\circ} \mathrm{c}$. The lyophilized samples were re-dissolved in methanol. The sample was filtered through $0.22 \mu \mathrm{m}$ syringe filter.

For reverse phase HPLC analysis, $20 \mu \mathrm{l}$ of sample was injected into Shimadzu HPLC system. The solvent system was methanol (A) and $0.1 \%$ formic acid in water (B) with a gradient time program from 0- 60 min with $\mathrm{B}$ ratio ranging from $5-70 \%$. The flow rate was kept constant at $1.5 \mathrm{ml} / \mathrm{min}$ with a maximum pressure of $300 \mathrm{kgf} / \mathrm{cm}^{2}$. Berberine standard dissolved in methanol were run in similar conditions. The peaks obtained for T. cordifolia extract and that for berberine standard was compared.

The extract was spotted onto silica gel 256GF TLC plates along side of berberine. The plate was developed in presaturated camag twin trough chamber with solvent system toluene, acetone and water in the ratio 5:15:1 up to $80 \mathrm{~mm}$. The plate was removed, dried, viewed and scanned at $256 \mathrm{~nm}$ and $366 \mathrm{~nm}$ using Camag TLC scanner with help of Wincats ${ }^{\mathrm{TM}}$ software.

The region of the TLC plates in sample spots having similar Rf to that of standard Berberine was scrapped off and mixed thoroughly with ethanol and centrifuged. The isolated fraction was lyophilized $(4.2 \mathrm{mg})$ and was further used for UPLC MS/MS Q-tof and in inhibition studies.

\section{Characterization of Berberine by UPLC ESI MS/MS Q-tof}

The isolated fraction obtained from TLC was subjected to UPLC MS/ MS Q-tof as described earlier. ${ }^{13} 10 \mu \mathrm{l}$ of fraction and berberine standard was injected. A mixture of $0.1 \%$ formic acid in water (A) and acetonitrile (B) was used as solvents with gradient time program from 0.0-6 min :10-95\% B, $6.5-9 \mathrm{~min}: 95-10 \% \mathrm{~B}$ with a flow rate of $0.3 \mathrm{~mL} / \mathrm{min}$ at $30^{\circ} \mathrm{c}$. Mode of ionization was positive electrospray ionization with capillary voltage set at $3.5 \mathrm{kV}$ and cone voltage of $30 \mathrm{~V}$. Nitrogen was used as both sheath gas and drying gas. The flow rate for sheath gas was $900 \mathrm{~L} / \mathrm{hr}$ and for drying gas it was $50 \mathrm{~L} / \mathrm{hr}$ and was set at temperature of $350^{\circ} \mathrm{C}$ and $135^{\circ} \mathrm{C}$ respectively. The back pressure was set at $1500 \mathrm{psi}$. The Q-tof data was collected for a range of $\mathrm{m} / \mathrm{z} 50$ and $\mathrm{m} / \mathrm{z} 1500$. The data was collected using $\mathrm{MS}^{\mathrm{E}}$ centroid technology which uses two collision energies $(6 \mathrm{eV}$ and $20-30 \mathrm{eV}$ ) to produce precursor and fragment ions. Mass calibration was done using leucine-enkephalin and the residual error was set at 2ppm. The accurate mass and composition of parent and daughter ions was calculated using Mass Lynx V 4.1 software.

\section{Inhibition of 5-Lipoxygenase}

The fraction isolated by HPTLC, was lyophilized, quantified and re dissolved in methanol. Efficacy of different concentrations of the isolated fraction and standard drug NDGA on inhibition of 5-LOX were determined using FOX assay ${ }^{14}$ with modifications. Briefly, $20 \mu \mathrm{l}$ of 5-LOX and $20 \mu \mathrm{l}$ of different concentrations of the fraction were mixed together and incubated at RT for $20 \mathrm{~min}$. To this $140 \mu \mathrm{M}$ of linoleic acid was added, mixed and incubated in dark for $20 \mathrm{~min}$. FOX reagent $(130 \mu \mathrm{l})$ was added, mixed and incubated again in dark for $30 \mathrm{~min}$. Absorbance was taken at $560 \mathrm{~nm}$. The percentage inhibition was calculated as (Absorbance of control-Absorbance of test)/ (Absorbance of control) $\times 100$. The $\mathrm{IC}_{50}$ values were calculated using GrapPad Prism 5.0 software.

\section{Docking studies}

The structure of human 5- lipoxygenase was downloaded from RCSB protein data bank (PDB ID: 3V99) (http://www.rcsb.org). The structure of berberine was drawn using Chemsketch (www.acdlabs.com/resources/ freeware/chemsketch). The structure of NDGA used as standard was downloaded from Chemspider (http://www.chemspider.com/ChemicalStructure.4375.html). Protein modification was performed using Swiss-PDB viewer and by AutoDock 4.0. During protein preparation all heteroatoms was removed except iron which is required for enzyme activity, polar hydrogen atoms added and Kollman charges was assigned to the protein macromolecule. For the binding of ligand with the protein, the binding site was determined having a dimension of $60 \mathrm{~A}^{\circ}$ around the active site with amino acid coordinates $17.650,-28.623,-26.503$ in B chain of the enzyme. During docking the protein was set rigid and docked by applying Lamarckian genetic algorithm with a maximum of 2500000 energy evaluations and RMSD tolerance of about $2.0 \mathrm{~A}^{\circ}$. The docked protein was visualized by using Discovery Studio 4.5 visualizer. The results were determined based on RMSD(root mean square deviation) and binding energy. ${ }^{15,16}$

\section{Statistical analysis}

The results were expressed as mean \pm standard deviation of three independent experiments. Statistical analysis was done using unpaired t-test using GraphPad prism $5.0^{\mathrm{TM}}$. A p value $\leq 0.05$ were considered as statistically significant.

\section{RESULT AND DISCUSSION}

HPLC chromatogram of berberine as standard showed a broad peak with retention time at $31.898 \mathrm{~min}$ at a wavelength of $350 \mathrm{~nm}$. Tinospora cordifolia methanolic extract chromatogram showed a peak of 31.477 corresponding to that of berberine standard under similar run conditions (Figure 1A, B). In HPTLC analysis an Rf value of 0.16 was obtained for berberine and the compounds in Tinospora cordifolia methanolic extracts was separated and a compound with similar Rf $(0.16 \mathrm{~cm})$ was obtained (Figure 2).

In UPLC total ion chromatogram a clean peak was obtained for berberine standard at $3.79 \mathrm{~min}$ and a peak at $3.73 \mathrm{~min}$ was obtained for Tinospora cordifolia methanolic extract indicating the presence of berberine (Figure 3A, B). In mass spectrometer mode a mass of $\mathrm{m} / \mathrm{z} 336.1240 \mathrm{~g} / \mathrm{mol}$ $\left[\mathrm{M}+\mathrm{H}^{+}\right]$was obtained for the berberine standard and compound with mass of $\mathrm{m} / \mathrm{z} 336.1243 \mathrm{~g} / \mathrm{mol}\left[\mathrm{M}+\mathrm{H}^{+}\right]$was obtained along with compounds having $\mathrm{m} / \mathrm{z}$ of $71.3502,121.6772,177.3363,220.4342,255.4086$, 296.1649, $366.1698408 .1442,466.8577,542.9118,584.9508 \mathrm{~g} / \mathrm{mol}$ $\left[\mathrm{M}+\mathrm{H}^{+}\right]$for Tinospora cordifolia methanolic extract (Figure 4A, B). This compound $\left(\mathrm{m} / \mathrm{z} 336.1243 \mathrm{~g} / \mathrm{mol}\left[\mathrm{M}+\mathrm{H}^{+}\right]\right)$was further fragmented to 

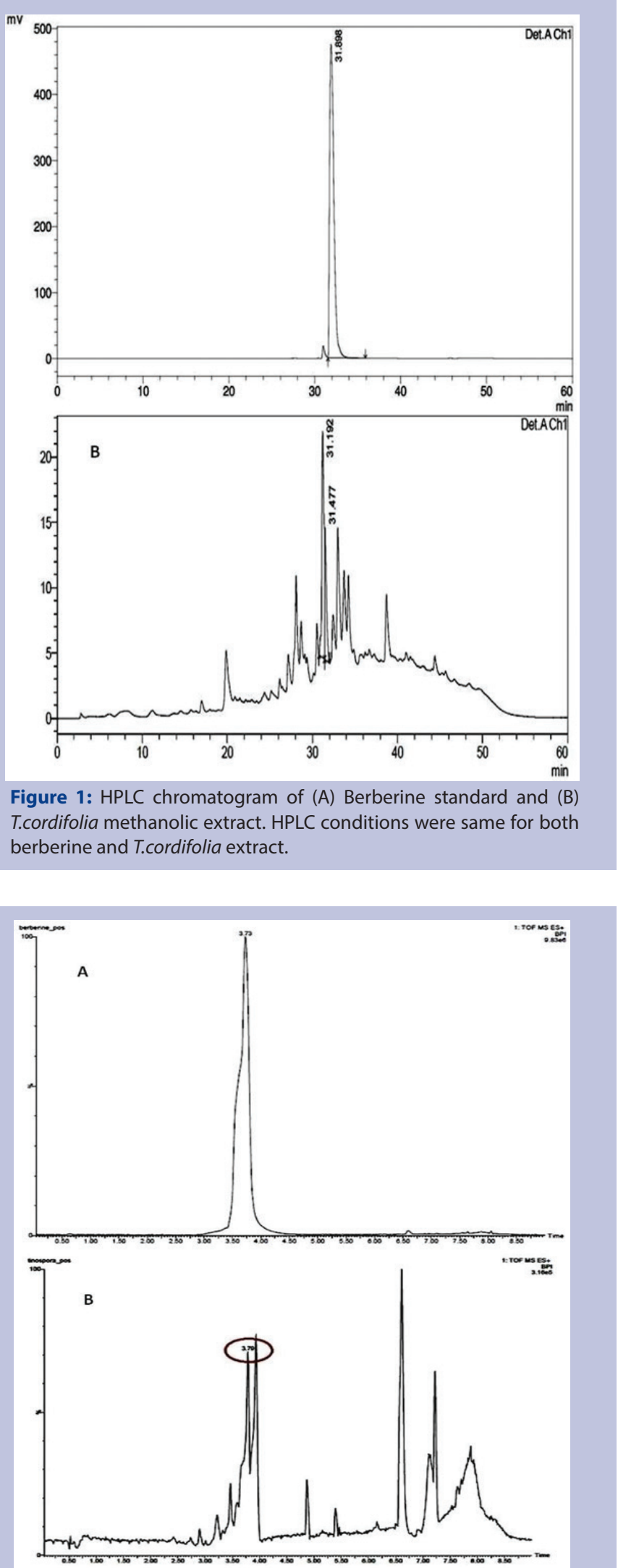

Figure 3: Total ion chromatogram obtained for (A) standard berberine and (B) T.cordifolia methanolic extract. A retention time of $3.79 \mathrm{~cm}$ and $3.73 \mathrm{~cm}$ was obtained for berberine and T.cordifolia methanolic extract respectively.

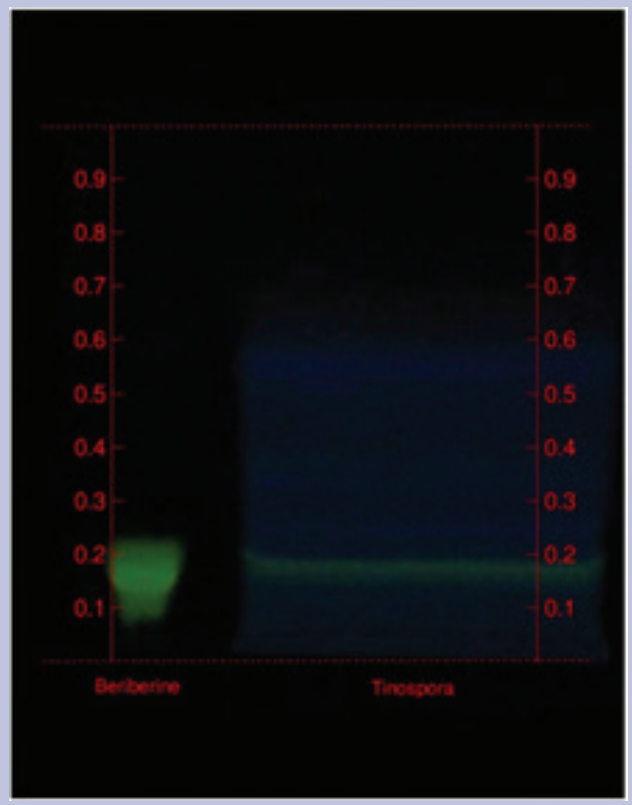

Figure 2: HPTLC chromatogram of Berberine standard and T.cordifolia. An Rf of 0.16 was observed for T.cordifolia methanolic extract which corresponds to the Rf of standard berberine.

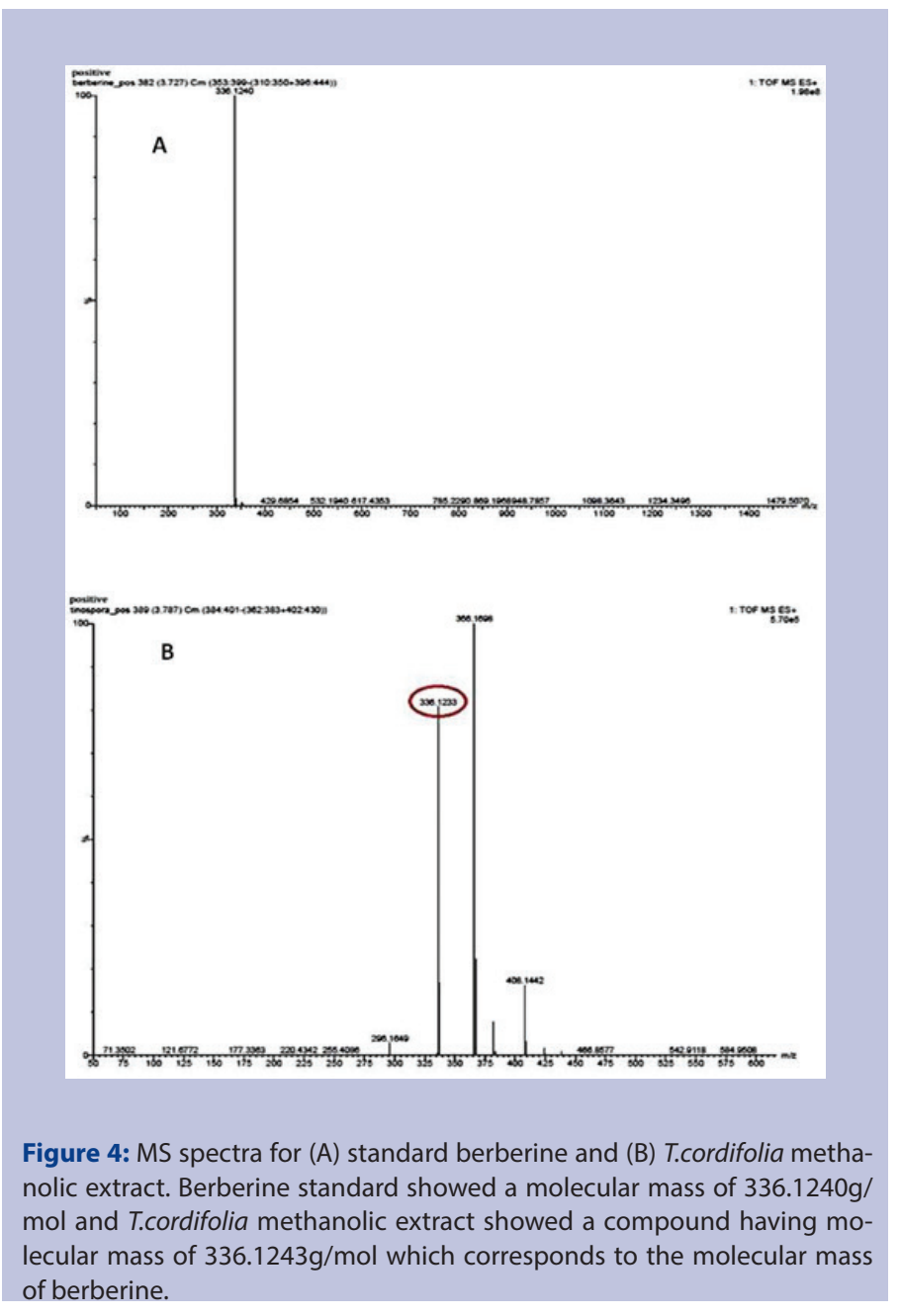




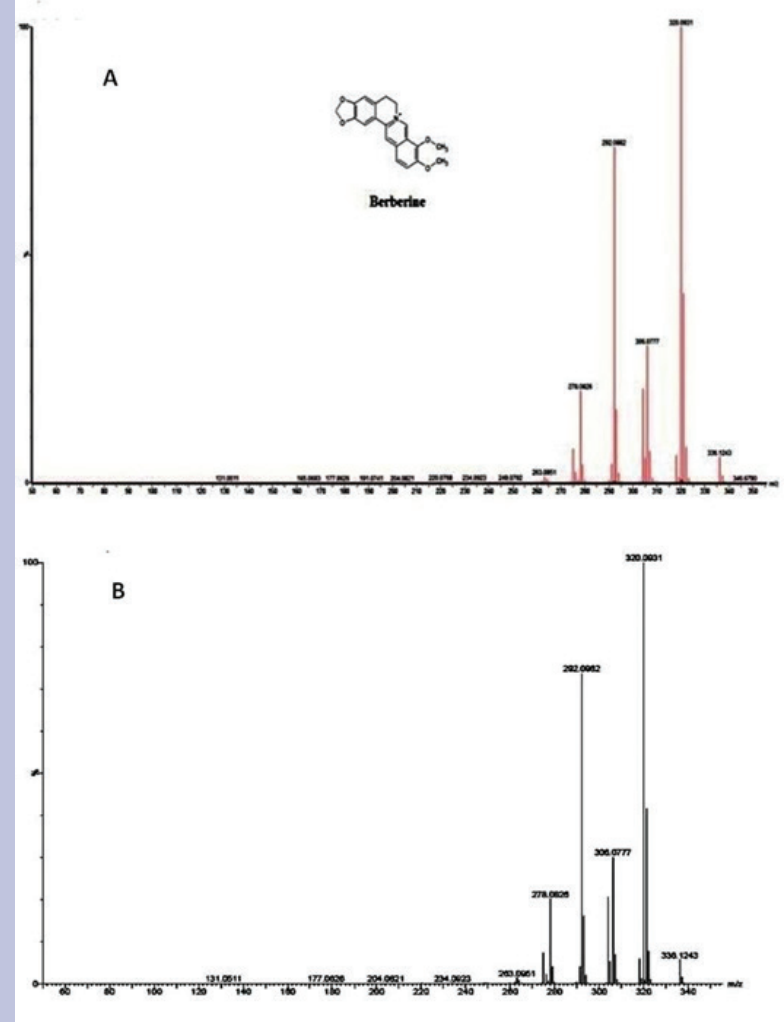

Figure 5: MS/MS fragmentation pattern for (A) Berberine standard and (B) T.cordifolia methanolic extract bioactive fraction.

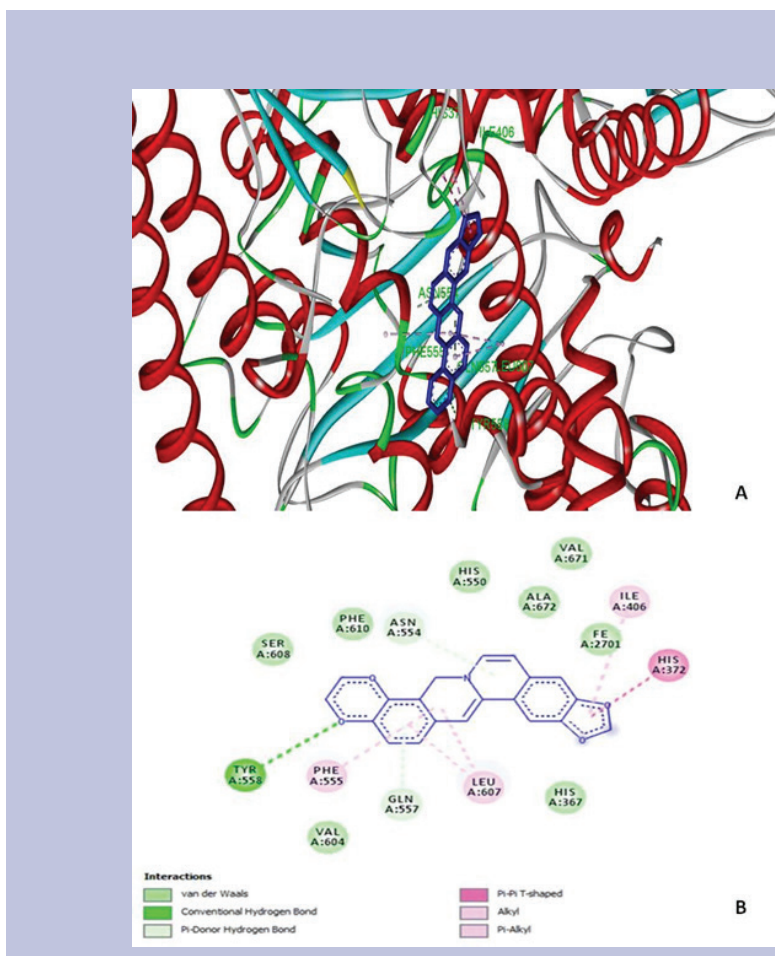

Figure 6: A) and (B). Docking of Berberine with 5 LOX active site showing different types of interactions. The interactions are shown as dotted lines.

Table 1: IC $C_{50}$ value and Binding energies of berberine were compared with that of NDGA. Better inhibition was observed by berberine than for NDGA towards 5 LOX. Binding of berberine was higher than NDGA as shown by its binding energy and Ki values. In silico docking of 5 LOX (PDB ID: 3V99) was in accordance to the in vitro data obtained. Values expressed as mean \pm S.D. *p value $<0.05$, \# $p$ value $<0.001$.

\begin{tabular}{ccccc}
\hline SI No & Compound & $\mathrm{IC}_{50}(\mu \mathrm{g} / \mathrm{mL})$ & Binding Energy $(\mathrm{kcal} / \mathrm{mol})$ & $\mathrm{Ki}$ \\
\hline 1 & Berberine & $0.041 \pm 0.0003^{*}$ & $-8.942 \pm 0.039665^{*}$ & $0.273 \pm 0.003 \mu \mathrm{M}^{*}$ \\
2 & NDGA & $2.75 \pm 0.05$ & $-7.186 \pm 0.170503$ & $5.604 \pm 1.618 \mu \mathrm{M}$ \\
\hline
\end{tabular}

obtain MS/MS fragmentation spectrum. MS/MS chromatogram showed similar fragmentation pattern for both standard berberine and compound from Tinospora cordifolia methanolic extract (Figure 5A, B). The accurate mass and the structure were elucidated by using Mass $\operatorname{Lynx}^{\mathrm{TM}}$ v4.1 software.

5LOX is a major enzyme involved in synthesis of pharmacologically important leukotriene and lipoxins which are mediators of inflammation. ${ }^{17}$ Leukotriens are involved in chemotaxis of granulocytes, its attachment to vascular cell walls, stimulate secretion of antibodies IgE, IgG and IgM, increased production of interleukin and plays role in pathogenesis of inflammatory arthritis, psoriasis, asthma, ${ }^{18}$ allergic rhinitis, inflammatory bowel and skin disease, osteoporosis, cancer and cardiovascular disease. ${ }^{11}$ Tinospora cordifolia have been used in Indian traditional medical system of ayurveda for treatment of various ailments and has reported to inhibit 5-LOX. ${ }^{19}$ Inhibition of 12-lipoxygenase by fractions containing protoberberine has described earlier. ${ }^{20}$ Berberine have shown to be anti-inflammatory and yet the pathway for the control of inflammation has to be elucidated. ${ }^{21}$ The fraction containing berberine inhibited 5-LOX with an $\mathrm{IC}_{50}$ of $0.041 \pm$ $0.0003 \mu \mathrm{g} / \mathrm{mL}$ as compared to that of NDGA (positive control) which showed an $\mathrm{IC}_{50}$ of $2.75 \pm 0.05 \mu \mathrm{g} / \mathrm{mL}$.
Docking of berberine with 5 Lox active site was done to determine the different types of interactions involved and the strength of binding was expressed as binding energy. A lower binding energy represents high binding efficiency of ligand with the receptor. ${ }^{22}$ Berberine showed a binding energy of $-8.942 \pm 0.039665 \mathrm{kcal} / \mathrm{mol}$ and the estimated inhibition constant, Ki towards 5 LOX was found to be $273.16 \pm 3.026 \mathrm{nM}$ as compared to the NDGA which has a binding energy of $-7.186 \pm 0.170503$ $\mathrm{kcal} / \mathrm{mol}$ and Ki 5.604 $\pm 1.618 \mu \mathrm{M}$ (Table 1). Docking revealed a strong binding of berberine than NDGA. Hydrogen bond was seen between berberine and amino acids Tyr 558, Asn554, Gln557 of A chain of 5 LOX. Hydrophobic interactions were seen between A chain His372, Ile406, Phe555 and Leu607 (Figure 6A, B). Inhibitory constant Ki for berberine was less than NDGA which is in accordance to the $\mathrm{IC}_{50}$ obtained. Statistical analysis revealed berberine to be a better inhibitor than NDGA used as positive control.

\section{CONCLUSION}

The study has confirmed the presence of berberine in Tinospora cordifolia by means of high end mass spectrometric analysis. The fraction containing berberine has been shown to inhibit 5-lipoxygenase which is involved in inflammatory pathway and interactions were demonstrated by means of docking. Tinospora cordifolia can be used as a source of berberine and 
possible anti inflammatory activity of Tinospora cordifolia may be attributed to the presence of berberine.

\section{ACKNOWLEDGEMENT}

The authors acknowledge support of DBT through the DBT BUILDER program (BT/ PR4800/INF/22/152/2012 dated 03/22/2012), School of Biosciences and Interuniversity Instrumentation Center, Mahatma Gandhi University, Kottayam, India for providing analytical instrument facility.

\section{CONFLICT OF INTEREST}

The authors declare no conflict of interest.

\section{ABBREVIATIONS USED}

HPLC: High performance liquid chromatography; HPTLC: High performance thin layer chromatography; UPLC ESI MS Qtof: Ultra performance liquid chromatography electrospray ionization mass spectrometer quadrupole time of flight; NDGA: Nordihydroguaiaretic acid; $\mathrm{IC}_{50}:$ Half maximal inhibitory concentration.

\section{REFERENCES}

1. Ghosh, S. \& Saha, S. Tinospora cordifolia: One plant, many roles. Anc. Sci. Life 2012;31(4): 151-9. https://doi.org/10.4103/0257-7941.107344; PMid:23661861 PMCid:PMC3644751

2. Patil, V. S. \& Malpathak, N. P. Micro-morphoanatomical approach for comparative analysis of Tinospora cordifolia (Willd.) Miers and its adulterant plant using SEM and Cryostat. Pharmacogn. J 2016;9(1):39-45. https://doi.org/10.5530/ pj.2017.1.8

3. Sharma U, Bala M, Kumar N, Singh B, Munshi RK, Bhalerao S. Immunomodulatory active compounds from Tinospora cordifolia. Journal of ethnopharmacology. 2012 Jun 14;141(3):918-26. https://doi.org/10.1016/j.jep.2012.03.027; PMid:22472109.

4. Goel, H. C. et al. Radioprotective Potential of an Herbal Extract of Tinospora cordifolia. J. Radiat. Res 2004;45(1):61-8. https://doi.org/10.1269/jrr.45.61.

5. Kulkarni, S. K. \& Dhir, A. Berberine: a plant alkaloid with therapeutic potential for central nervous system disorders. Phyther. Res 2010;24(3):317-24. https://doi. org/10.1002/ptr.2968p; PMid:19998323.

6. Ortiz, L. M. G., Lombardi, P., Tillhon, M. \& Scovassi, A. I. Berberine, an epiphany against cancer. Molecules 2014;19:12349-67. https://doi.org/10.3390/molecules190812349; PMid:25153862.

7. Yong, Y., Kai, H., Bao-Shun, Z. \& Xue-Gang, L. Study on interaction between plasmid DNA and berberine derivatives with aliphatic chain by fluorescence analysis. Pharmacogn. Mag 2014;10(38):97-100. https://doi.org/10.4103/09731296.131017; PMid:24914272 PMCid:PMC4048568.

8. Srinivasan, G., Unnikrishnan, K., Rema Shree, A. \& Balachandran, I. HPLC estimation of berberine in Tinospora cordifolia and Tinospora sinensis. Indian J. Pharm. Sci 2008;70(1): 96-99. https://doi.org/10.4103/0250-474X.40341;
PMid:20390090 PMCid:PMC2852071

9. Flamini, R., De Rosso, M. \& Bavaresco, L. Study of Grape Polyphenols by Liquid Chromatography-High-Resolution Mass Spectrometry (UHPLC/QTOF) and Suspect Screening Analysis. J. Anal. Methods Chem 2015;2015:1-10. https:// doi.org/10.1155/2015/350259; PMid:25734021 PMCid:PMC4334975.

10. Purushothaman, A. \& Pemiah, B. Ultra high performance liquid chromatographyultraviolet-electrospray ionization-micrOTOF-Q || analysis of flavonoid fractions from Jatropha tanjorensis. Pharmacogn. Mag 2014;10: 472-79. https://doi. org/10.4103/0973-1296.139776; PMid:25298662 PMCid:PMC4189260.

11. Werz, O. Inhibition of 5-lipoxygenase product synthesis by natural compounds of plant origin. Planta Med 2007;73(13):1331-57. https://doi.org/10.1055/ s-2007-990242; PMid:17939102.

12. Eshwarappa, R. B. et al. Anti-Lipoxygenase activity of leaf gall extracts of Terminalia chebula (Gaertn.) Retz. (Combretaceae). Pharmacognosy Res 2016;8:(1)78-82. https://doi.org/10.4103/0974-8490.171103; PMid:26941541 PMCid:PMC4753765.

13. Abhimannue, A. P., Mohan, M. C. \& B, P. K. Inhibition of Tumor Necrosis Factor- $\alpha$ and Interleukin-1 $\beta$ Production in Lipopolysaccharide-Stimulated Monocytes by Methanolic Extract of Elephantopus scaber Linn and Identification of Bioactive Components. Appl. Biochem. Biotechnol 2016;179(3):427-43. https://doi.org/10.1007/ s12010-016-2004-0; PMid:26875087.

14. Waslidge N B, Hayes DJ. A colorimetric method for the determination of lipoxygenase activity suitable for use in a high throughput assay format. Anal Biochem. 1995;231(2):354-58. https://doi.org/10.1006/abio.1995.0063; PMid:8594985.

15. Kumar M, Dagar A, Gupta VK, Sharma A. In silico docking studies of bioactive natural plant products as putative DHFR antagonists. Med. Chem. Res 2014;23(2):810-17. https://doi.org/10.1007/s00044-013-0654-9.

16. Anu P. Abhimannue, Mohind C. Mohan, Esha Kuriakose, P. K. B. In Silico Screening of Bioactive Molecules From Elephantopus Scaber Linn. for Binding with Cardiac Potassium Ion Channels, Kir2.1 and Kir3.1. J Pract Biochem Biophys. 2016;1:27-33

17. Aparoy P, Reddy RN, Guruprasad L, Reddy MR, Reddanna P. Homology modeling of 5-lipoxygenase and hints for better inhibitor design. J Comput Aided Mol Des. 2008;22(9):611-19. https://doi.org/10.1007/s10822-008-9180-0; PMid:18231862

18. Gilbert NC. et al. Conversion of human 5-lipoxygenase to a 15-lipoxygenase by a point mutation to mimic phosphorylation at Serine-663. FASEB J 2012;26(8):3222-9. https://doi.org/10.1096/fj.12-205286; PMid:22516296 PMCid:PMC3405276

19. Jacob, J., Prakash, K. B., Abhimannue, A. P., Mohind, M. \& Babu, B. M. Inhibition of lipoxygenase enzymes by extracts of Tinospora cordifolia: A study of enzyme kinetics. J. Nat. Prod 2014;7:203-09.

20. Rackova, L., Oblozinsky, M., Kostalova, D., Kettmann, V. \& Bezakova, L. Free radical scavenging activity and lipoxygenase inhibition of Mahonia aquifolium extract and isoquinoline alkaloids. J. Inflamm 2007;4(1):4-15. https://doi. org/10.1186/1476-9255-4-4; PMid:17306030 PMCid:PMC1803772

21. Kuo, C.-L., Chi, C.-W. \& Liu, T.-Y. The anti-inflammatory potential of berberine in vitro and in vivo. Cancer Lett 2015;203(2):127-37. https://doi.org/10.1016/] canlet.2015.01.015. https://doi.org/10.1016/j.canlet.2003.09.002.

22. Priya, R. et al. Molecular docking and molecular dynamics to identify a nove human immunodeficiency virus inhibitor from alkaloids of Toddalia asiatica. Pharmacogn. Mag 2015;11(3):414-22.

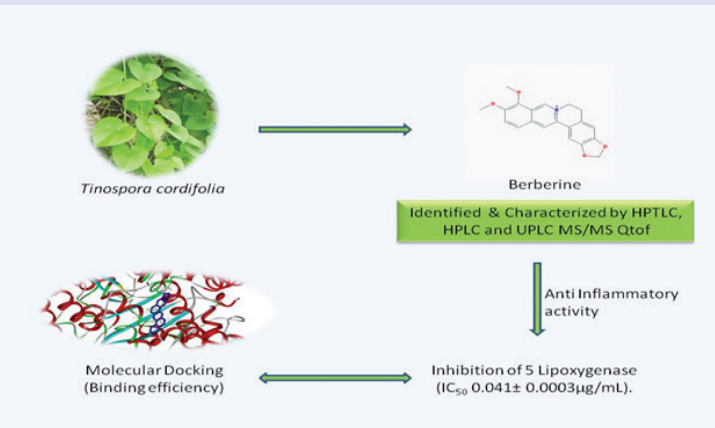

\section{GRAPHICAL ABSTRACT}

\section{SUMMARY}

- Presence of berberine in Tinospora cordifolia was confirmed by means of high end mass spectrometry analysis (UPLC MS/MS Qtof). The fraction containing berberine was checked for anti-inflammatory activity which showed an inhibition on activity of 5 -lipoxygenase $\left(I C_{50} 0.041 \pm 0.0003 \mu \mathrm{g} / \mathrm{mL}\right)$. The interaction between berberine and 5 lipoxygenase was demonstrated by molecular docking studies. The anti-inflammatory activity of Tinospora cordifolia may be due to the presence of berberine.

\section{ABOUT AUTHORS}

Prakash Kumar B: He is working as Associate Professor in Biochemistry at School of Biosciences, Mahatma Gandhi University, Kerala, India. He obtained his Ph.D in 1997 from Sree Chithira Tirunal Insititute for Medical Science and Technology, India. Dr. Prakash is currently working on anti inflammatory, anti obesity biomolecules from Plants and Ayurvedic medicines. 


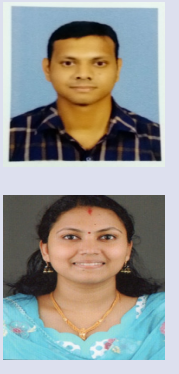

Mohind C. Mohan: He is currently involved in identifying and characterizing anti inflammatory biomolecules from Ayurvedic medicines.

Anu P. Abhimannue: Has carried out works in determining possible anti inflammatory and anti carcinogenic lead molecules from medicinal plants.

Cite this article: Mohan MC, Abhimannue AP, Prakash KB. Identification and Characterization of Berberine in Tinospora cordifolia by Liquid Chromatography Quadrupole Time of Flight Mass Spectrometry (LC MS/MS Q-tof) and Evaluation of its anti Inflammatory Potential. Pharmacogn J. 2017;9(3):350-5. 